\title{
To what extent do weight gain and eating avidity during infancy predict later adiposity?
}

\author{
Charlotte M Wright ${ }^{1, *}$, Katherine Marie Cox ${ }^{1}$, Andrea Sherriff ${ }^{2}$, Maria Franco-Villoria ${ }^{3}$, \\ Mark S Pearce ${ }^{4}$, Ashley J Adamson ${ }^{4}$ and Gateshead Millennium Study core team $†$ \\ 'Community Child Health, PEACH Unit, School of Medicine, MVLS, QMH Tower, Yorkhill Hospitals, Glasgow \\ G3 8SJ, UK: ${ }^{2}$ Glasgow Dental School, MVLS, Glasgow, UK: ${ }^{3}$ Department of Statistics, University of Glasgow, \\ Glasgow, UK: ${ }^{4}$ Institute of Health and Society, Newcastle University, Newcastle upon Tyne, UK
}

Submitted 3 December 2010: Accepted 8 July 2011: First published online 18 October 2011

\begin{abstract}
Objective: To determine the extent to which weight gain and eating behaviours in infancy predict later adiposity.

Design: Population-based, prospective, longitudinal birth cohort study. Weights collected in infancy were used to calculate $Z$-scores for weight gain to age 1 year conditional on birth weight (CWG). To avoid multiple significance tests, variables from the parent questionnaire completed at age 1 year describing eating avidity were combined using general linear modelling to create an infancy avidity score. Anthropometry, skinfold thicknesses and bioelectrical impedance data collected at age 7-8 years were combined using factor analysis, to create an adiposity index.

Setting: Gateshead, UK.

Subjects: Members of the Gateshead Millennium Study cohort with data at both time points ( $n$ 561).

Results: CWG in infancy significantly predicted adiposity at age 7 years, but related more strongly to length and lean mass. High adiposity ( $>90$ th internal percentile) at age 7 years was significantly associated with high CWG (relative risk $2 \cdot 76$; $95 \% \mathrm{CI}$ $1 \cdot 5,5 \cdot 1)$ in infancy, but less so with raised $(>74$ th internal percentile) eating avidity in infancy (relative risk $1 \cdot 87 ; 95 \%$ CI $0 \cdot 9,3 \cdot 7$ ). However, the majority of children with high weight gain $(77 \cdot 6 \%)$ or avidity $(85.5 \%)$ in infancy did not go on to have high adiposity at age 7 years.

Conclusions: Rapid weight gain in infancy and the eating behaviours which relate to it do predict later adiposity, but are more strongly predictive of later stature and lean mass.
\end{abstract}

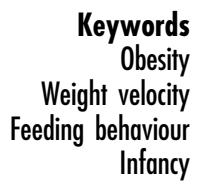

A number of studies have found significant associations between rapid infancy weight gain and later overweight $^{(1)}$, leading to the suggestion that prevention ${ }^{(2,3)}$ and even treatment of childhood obesity ${ }^{(4,5)}$ should begin as early as the first year of life. However, weight gain in infancy reflects growth in bone and muscle as well as fat and some infants will be showing rapid gain in height or lean mass rather than adiposity ${ }^{(6)}$. Thus while on average rapid weight gain may predict later adiposity, what is not clear is how well it would prospectively identify individual children at risk. There is also recent research that suggests there are distinctive childhood eating behaviours related to overweight which may reflect an inherent tendency to overeat ${ }^{(7)}$, so eating behaviour in infancy

$\dagger$ Gateshead Millennium Study core team: Ashley Adamson, Anne Dale, Robert Drewett, Ann Le Couteur, Paul McArdle, Kathryn Parkinson, Mark S. Pearce, John J. Reilly, Charlotte M. Wright. could predispose to, or protect against, later obesity ${ }^{(7,8)}$. Apart from studies examining how the type and style of milk feeding relates to later obesity ${ }^{(9-11)}$, we currently know little about eating behaviour in infancy and even less about how it tracks on to later adiposity or eating style. We hypothesised that eating avidity, a global term to denote enthusiasm and hunger for food, might be a useful predictor of gain in fat.

The Gateshead Millennium Study was set up in order to examine infant growth and weight gain and how this relates to eating behaviour, prospectively measured from birth $^{(12)}$. These children have now been followed into childhood where measures of body composition have been collected. We could thus use these data to explore the extent to which infancy weight gain and eating avidity predict adiposity later in childhood and the extent to which these can specifically identify children at risk of later adiposity. 


\section{Methods}

The Gateshead Millennium Study aimed to recruit a whole population cohort of 1029 Gateshead-resident children within one week of birth between June 1999 and May $2000^{(13)}$ and the mothers of $81 \%$ agreed to take part. The children were studied prospectively using parent report questionnaires shortly after birth, at 6 weeks and at 4, 8 and 12 months. The cohort has since been re-traced at school entry, parent report questionnaires completed at age $5-8$ years, and a range of anthropometric and body composition measures collected at age $7-8$ years ${ }^{(12)}$. The cohort was predominantly (98\%) white Caucasian, but the present analyses excluded a small number of Haredi (ultra orthodox Jewish) children who had follow-up data at age 7 years, as these children had very different growth and feeding patterns in the first year ${ }^{(14)}$. Ethical approval for all phases of the study was granted by Gateshead and South Tyneside Local Research Ethics Committee.

\section{Growth and body composition measures}

Routinely collected clinic weights were returned with questionnaires by parents throughout the first year. At age 13 months, children were seen by research nurses who measured length (Raven rollameter) and weight (Seca scales). At age 7-8 years children were visited at school where research staff measured height (Leicester portable measure) and weight and leg-to-leg bioelectrical impedance (BIA) using the Tanita TBF-300MA. Measurements were also taken of triceps and subscapular skinfolds, using Holtain skinfold callipers, and waist circumference using a non-stretchable tape measure. Length, height, weight and BMI were converted into $Z$-scores compared with the UK 1990 reference ${ }^{(15)}$. Change in weight $Z$-score from birth to 12 months conditional on birth weight ${ }^{(16)}$ was calculated to give a figure for conditional infancy weight gain (CWG). Waist and skinfold thicknesses were also converted into $Z$-scores using the best available external references ${ }^{(17,18)}$ and the mean skinfolds' $Z$-score taken. The BIA data were converted into $Z$-scores for fat mass and lean mass, standardised for height, gender and age, using reference data from the ALSPAC (Avon Longitudinal Study of Parents and Children) cohort ${ }^{(19)}$.

Factor analysis, with a promax rotation, on the logged data was undertaken for thirteen measures of size and/or adiposity: height, width of shoulders, diameters of elbow, wrist, hip and knee, waist circumference, skinfold measures of the subscapular, triceps, biceps and suprailiac, and the impedance-based measures of fat and lean mass, as well as age. This produced a three-component model which explained $79 \%$ of the overall variance. The first component consisted mainly of measures of fat mass (waist circumference, the four skinfold measurements and BIA fat mass), while the second consisted mainly of measures of size (height, shoulders, elbow, wrist, knee and lean mass) and the third consisted mainly of age. The first factor results were thus used to create an adiposity index.

Internal centiles adjusted for height were calculated separately for girls and boys. Children with values above the 75th and 90th internal centiles for any measure were defined as having raised or high values, respectively.

\section{Infancy eating avidity measures}

The parent report questionnaire at 12 months included twenty-five questions drawn from previous research and clinical practice selected to describe enthusiasm and appetite for or aversion to food, as well as any oro-motor feeding difficulties. Many of these correlated significantly with both weight gain and appetite at different ages, but even the most predictive of these variables (appetite) individually predicted only a tiny proportion of the variance in weight to 1 year $(4 \%)^{(20)}$. We thus needed some sort of data reduction and summarising process to form a composite measure of infancy avidity eating behaviours (avidity score).

We first explored these variables using principal components analysis, but while this produced apparently coherent factors, they were unrelated to weight gain, even when component variables were known to be individually predictive of weight gain ${ }^{(21)}$. We therefore adopted a new approach and used general linear regression modelling to identify which variables independently predicted conditional weight gain (CWG) from birth to 1 year. All variables that showed a borderline univariable association with $\mathrm{CWG}(P \leq 0 \cdot 2)$ were added to a multivariable general linear model. Variables with insignificant $(P>0.05)$ coefficients were removed from the model successively until only variables that were independently predictive $(P \leq 0 \cdot 05)$ remained. These six items (see Table 4 ) were then combined by summing each regression coefficient, multiplied by the response to each item, to produce each child's avidity score.

The association of CWG and avidity with measures of stature and adiposity at age $7-8$ years was assessed using Pearson's bivariate and partial correlations and the association of high weight gain or avidity with high adiposity using the $\chi^{2}$ test. Post boc analysis would suggest that with about 500 subjects the minimum detectable correlation would be about $0 \cdot 18$. This number would give $80 \%$ power to detect a statistically significant relative risk of 2.5 between any child with values in the top $10 \%$ of centiles compared with the remainder.

\section{Results}

The original cohort comprised 1029 infants (51\% male), of whom 764 had growth data at age 1 year and 585 had body composition data at age $7-8$ years, after exclusion of seven Haredi children. The growth characteristics of the cohort members in infancy and at follow-up when aged 7 years are shown in Table 1. Infancy CWG showed a 
Table 1 Growth and body composition characteristics of cohort members in infancy at age 1 year and at follow-up at age 7 years: 561 members of Gateshead Millennium Study cohort with data at both time points

\begin{tabular}{|c|c|c|c|c|c|c|}
\hline \multirow[t]{2}{*}{ (a) Age 1 year } & \multicolumn{3}{|c|}{ All in cohort } & \multicolumn{3}{|c|}{ All with infant avidity score data } \\
\hline & $n$ & Mean & SD & $n$ & Mean & SD \\
\hline Age at health check (years) & 811 & $1 \cdot 16$ & $0 \cdot 10$ & 566 & $1 \cdot 14$ & 0.08 \\
\hline CWG (birth to 12 months) & 826 & $0 \cdot 17$ & 0.97 & 580 & $0 \cdot 18$ & 0.96 \\
\hline Length $(\mathrm{cm})$ & 811 & $78 \cdot 1$ & $4 \cdot 18$ & 566 & $77 \cdot 8$ & $4 \cdot 39$ \\
\hline Length SDS* & 810 & 0.51 & 1.06 & 565 & 0.51 & 1.07 \\
\hline BMI $\left(\mathrm{kg} / \mathrm{m}^{2}\right)$ & 810 & $17 \cdot 0$ & $1 \cdot 37$ & 565 & $17 \cdot 0$ & $1 \cdot 35$ \\
\hline BMI SDS* & 810 & -0.32 & $1 \cdot 05$ & 565 & -0.29 & 1.03 \\
\hline
\end{tabular}

(b) Age 7 years

All in cohort

\begin{tabular}{|c|c|c|c|c|c|}
\hline & & & & & \\
\hline & \multirow[b]{2}{*}{$n$} & \multirow[b]{2}{*}{ Mean } & \multirow[b]{2}{*}{ SD } & \multicolumn{2}{|c|}{ Above external 98th centile } \\
\hline & & & & $\%$ & $n$ \\
\hline Age at follow-up (years) & 585 & $7 \cdot 45$ & 0.5 & - & - \\
\hline Height $(\mathrm{cm})$ & 585 & $125 \cdot 0$ & $5 \cdot 8$ & - & - \\
\hline Height SDS* & 585 & $0 \cdot 14$ & $1 \cdot 0$ & $3 \cdot 6$ & 21 \\
\hline BMI $\left(\mathrm{kg} / \mathrm{m}^{2}\right)$ & 583 & $16 \cdot 9$ & $2 \cdot 5$ & - & - \\
\hline BMI SDS* & 583 & 0.44 & $1 \cdot 1$ & $9 \cdot 1$ & 53 \\
\hline Waist (cm) & 560 & $56 \cdot 8$ & $6 \cdot 3$ & - & - \\
\hline Waist SDSt & 560 & 0.59 & $1 \cdot 1$ & $11 \cdot 1$ & 64 \\
\hline Triceps skinfold (mm) & 561 & $11 \cdot 5$ & 4.9 & - & - \\
\hline Subscapular skinfold (mm) & 546 & $8 \cdot 65$ & $5 \cdot 6$ & - & - \\
\hline Mean skinfolds SDS‡ & 539 & 0.54 & $1 \cdot 0$ & $8 \cdot 0$ & 43 \\
\hline BIA (ohms) & 563 & 634 & 67 & - & - \\
\hline Fat mass SDS $(B \mid A) \S$ & 562 & 0.49 & $0 \cdot 8$ & $3 \cdot 4$ & 20 \\
\hline Lean mass SDS $(\mathrm{BIA}) \S$ & 563 & $-0 \cdot 14$ & $1 \cdot 0$ & $2 \cdot 6$ & 15 \\
\hline Adiposity index $\|$ & 442 & 0.014 & $2 \cdot 3$ & - & - \\
\hline
\end{tabular}

CWG, conditional weight gain; SDS, standard deviation score; BIA, bioelectrical impedance.

${ }^{*}$ Compared with UK 1990 reference ${ }^{(15)}$.

tCompared with McCarthy reference ${ }^{(17)}$.

‡Compared with Tanner and Whitehouse skinfold reference ${ }^{(18)}$.

§Compared with ALSPAC (Avon Longitudinal Study of Parents and Children) reference ${ }^{(19)}$.

IIInternally standardised.

significant association with adiposity at age 7 years, but a stronger association with height, BMI and lean mass (Table 2). Children with the most rapid CWG in infancy were nearly three times more likely than the remainder to go on to have high adiposity at age 7 years (Table 3 ). Children with high BMI at age 1 year were also more likely to go on to have high adiposity, but the two effects were not additive. Having relatively high weight gain and BMI was also associated with some increased risk of going on to have high adiposity (relative risk $=1.95$ ).

Twelve individual eating variables univariably predicted CWG across the first year at $P \leq 0 \cdot 2$ and of these, six remained independently predictive in a multiple linear regression model (Table 4). These variables were used to construct the avidity score available for 561 eligible children who also had weight data at 1 year. This score explained $8 \%$ of the variability in CWG from 0 to 12 months (Fig. 1). There was substantial clustering of scores in the centre of the distribution, with 219 (37\%) children having the median value, but then a much wider spread in both directions; the $26 \%$ of children with values above the median were thus categorised as having a raised avidity score (Fig. 1).

At age $7-8$ years, although correlation coefficients were low, the avidity score was significantly associated with both height and BMI in boys. A weak and non-significant correlation with adiposity became weaker still after adjustment for height (Table 5). Children with a raised avidity score in infancy showed only a borderline tendency to be in the high adiposity range (above 90th centile) at 7 years (Table 3). Children with avidity score data did not differ from the cohort as a whole at age 1 year (see Table 1 ) or in adiposity score at age 7-8 years (data not shown).

\section{Discussion}

Our aim in the present analysis was to explore the extent to which weight gain and eating behaviour in infancy can predict the risk of future obesity in childhood. While CWG did significantly relate to later adiposity, it was much more strongly related to size than to adiposity. A number of studies have now shown a relationship between early weight gain and later adiposity ${ }^{(5,6,22-25)}$, which demonstrates that many children destined to become obese are probably already laying down excess fat in infancy. However, those studies which also considered the relationship between adiposity and height or lean mass also generally found a stronger association with 
Table 2 Association of conditional weight gain in infancy with growth and body composition measures at age 7 years: Gateshead Millennium Study cohort

\begin{tabular}{|c|c|c|c|c|c|}
\hline & \multirow[b]{2}{*}{$n$} & \multicolumn{2}{|c|}{ Univariable correlation coefficient } & \multicolumn{2}{|c|}{ Partial correlation adjusted for heigh } \\
\hline & & $r$ & $P$ & $r$ & $P$ \\
\hline \multicolumn{6}{|l|}{ All } \\
\hline Height & 551 & 0.48 & $<0.001$ & - & \\
\hline $\mathrm{BMI}$ & 549 & 0.45 & $<0.001$ & $0 \cdot 32$ & $<0.001$ \\
\hline Lean mass (BIA) & 549 & 0.33 & $<0.001$ & $0 \cdot 30$ & $<0.001$ \\
\hline Adiposity index & 430 & 0.31 & $<0.001$ & $0 \cdot 14$ & 0.004 \\
\hline \multicolumn{6}{|l|}{ Boys } \\
\hline Height & 275 & 0.48 & $<0.001$ & - & \\
\hline BMI & 289 & 0.39 & $<0.001$ & $0 \cdot 26$ & 0.002 \\
\hline Lean mass (BIA) & 275 & $0 \cdot 30$ & $<0.001$ & $0 \cdot 26$ & $0 \cdot 001$ \\
\hline Adiposity index & 213 & 0.24 & $<0.001$ & 0.08 & 0.244 \\
\hline \multicolumn{6}{|l|}{ Girls } \\
\hline Height & 276 & 0.49 & $<0.001$ & - & \\
\hline BMI & 275 & 0.38 & $<0.001$ & $0 \cdot 36$ & $<0.001$ \\
\hline Lean mass $(\mathrm{BIA})$ & 274 & 0.51 & $<0.001$ & 0.39 & $<0.001$ \\
\hline Adiposity index & 217 & 0.43 & $<0.001$ & 0.24 & $<0.001$ \\
\hline
\end{tabular}

BIA, bioelectrical impedance.

Values are Pearson's correlation coefficients $(r)$ of each measure, expressed as a Z-score, with conditional weight gain from birth to 12 months.

Table 3 Relative risk (RR) of having high adiposity (>90th internal percentile) at age 7 years relative to different thresholds and combinations of measures collected at age 1 year: Gateshead Millennium Study cohort

\begin{tabular}{|c|c|c|c|c|c|c|c|}
\hline & \multicolumn{2}{|c|}{$\begin{array}{l}\text { Percentage (number) } \\
\text { of those with } \\
\text { adiposity score } \\
\text { above this threshold }\end{array}$} & \multicolumn{2}{|c|}{$\begin{array}{c}\text { Percentage (number) of those } \\
\text { above this threshold with high } \\
\text { adiposity (>90th percentile) at } \\
\text { age } 7 \text { years }\end{array}$} & \multicolumn{2}{|c|}{$\begin{array}{l}\mathrm{RR}(95 \% \mathrm{Cl}) \\
\text { compared with } \\
\text { remainder }\end{array}$} & \multirow[b]{2}{*}{$P$} \\
\hline & $\%$ & $n$ & $\%$ & $n$ & $\mathrm{RR}$ & $95 \% \mathrm{Cl}$ & \\
\hline All with adiposity score at age 7 years & 100 & 456 & $9 \cdot 9$ & 42 & & & \\
\hline \multicolumn{8}{|l|}{ At age 1 year } \\
\hline Weight gain $>90$ th internal percentile & $11 \cdot 4$ & 49 & $22 \cdot 4$ & 11 & $2 \cdot 76$ & $1 \cdot 5,5 \cdot 1$ & 0.004 \\
\hline BMI $>90$ th internal percentile & $8 \cdot 4$ & 36 & $16 \cdot 7$ & 6 & $1 \cdot 80$ & $0 \cdot 8,4 \cdot 0$ & $0 \cdot 128$ \\
\hline Avidity $>74$ th internal percentile & $25 \cdot 2$ & 83 & $14 \cdot 5$ & 12 & $1 \cdot 87$ & $0 \cdot 9,3 \cdot 7$ & 0.082 \\
\hline BMI and weight gain >90th internal percentile & $4 \cdot 3$ & 18 & $27 \cdot 8$ & 5 & $3 \cdot 12$ & $1 \cdot 4,7 \cdot 0$ & 0.022 \\
\hline BMI or weight gain >90th internal percentile & $17 \cdot 2$ & 73 & $19 \cdot 2$ & 14 & $2 \cdot 32$ & $1 \cdot 3,4 \cdot 2$ & 0.007 \\
\hline BMI and weight gain $>75$ th internal percentile & $14 \cdot 2$ & 60 & $16 \cdot 7$ & 10 & 1.95 & $1 \cdot 0,3 \cdot 8$ & 0.048 \\
\hline $\mathrm{BMI}>75$ th and avidity $>74$ th internal percentile & $8 \cdot \overline{7}$ & 28 & $17 \cdot 9$ & 5 & $2 \cdot 20$ & $0.9,5 \cdot 3$ & 0.093 \\
\hline
\end{tabular}

later height than with fat mass ${ }^{(5,6,23,25)}$. If a majority of children with rapid weight gain in infancy are growing fast, rather than becoming fat, this would be a non-specific way of predicting future risk.

We had hypothesised that avid eating behaviours might be more a specific predictor of later adiposity, but in fact if anything they were less specific and their only significant association was with attained height. Rapid growth requires high nutrient intake, so it is plausible that infancy eating avidity would be driven by rapid growth at least as much as by any tendency to overeat and become obese. There has been little previous work relating infant eating avidity to growth or weight gain, apart from one, which found associations between milk feeding vigour and concurrent skinfold thicknesses in healthy infants ${ }^{(11)}$ as well as with BMI in the same infants at age 6 years ${ }^{(10)}$. A number of studies in childhood have found relationships between child eating behaviour and overweight or adiposity $^{(26-29)}$, but these were not prospective, making it difficult to distinguish cause and effect. One study has shown that child eating behaviours track through mid childhood $^{(30)}$. Recent work in this area has suggested that childhood eating behaviours associated with adiposity are quite strongly heritable ${ }^{(31)}$ and thus one might expect that there would be behavioural associations with adiposity present at the earliest age. However, the apparent degree of heritability increases with the age of the children studied $^{(32)}$, suggesting that a heritable tendency to overeat may emerge later than the age studied here, once children are exposed to the family and wider food environment.

A weakness of the present study is that under half of the cohort had full data at the age of 7 years, but this level of attrition is comparable to other studies of this long duration when examining multiple measures ${ }^{(19)}$, and there were no systematic differences between those with full data and those without. While this may lessen overall representativeness, it should not invalidate the internal relationships revealed.

While BMI is highly correlated with measures of adiposity and is often a useful proxy, it can nevertheless 
Table 4 Variables independently associated with conditional weight gain from birth to 12 months in general linear regression model: Gateshead Millennium Study cohort

\begin{tabular}{|c|c|c|c|c|c|c|}
\hline \multirow[b]{2}{*}{ Item } & \multicolumn{3}{|c|}{ Univariable analysis } & \multicolumn{3}{|c|}{ Multivariable analysis* } \\
\hline & $n$ & Mean & $95 \% \mathrm{Cl}$ & $P$ & B & $P$ \\
\hline Prefers drinks to food & & & & 0.080 & & $0 \cdot 001$ \\
\hline Often & 21 & 0.570 & $0.20,0.94$ & & 0.78 & \\
\hline Sometimes/rarely & 539 & $0 \cdot 201$ & $0 \cdot 12,0 \cdot 28$ & & 0 & \\
\hline Holds food in mouth & & & & 0.009 & & 0.024 \\
\hline Often/sometimes & 146 & 0.039 & $-0 \cdot 11,0 \cdot 19$ & & $-0 \cdot 20$ & \\
\hline Rarely & 414 & $0 \cdot 278$ & $0 \cdot 19,0.37$ & & 0 & \\
\hline Cries/screams during meals & & & & 0.047 & & 0.037 \\
\hline Often/sometimes & 60 & -0.014 & $-0.25,0.22$ & & $-0 \cdot 28$ & \\
\hline Rarely & 500 & $0 \cdot 243$ & $0 \cdot 16,0.33$ & & 0 & \\
\hline Is your baby feeding enough? & & & & 0.001 & & 0.002 \\
\hline No/not always & 63 & $-0 \cdot 173$ & $-0.42,0.08$ & & -0.49 & \\
\hline Yes & 497 & 0.264 & $0 \cdot 18,0.35$ & & 0 & \\
\hline How is your baby's appetite? & & & & & Total & 0.003 \\
\hline Average & 67 & -0.046 & $-0.28,0.18$ & 0.004 & -0.50 & 0.004 \\
\hline Good & 218 & $0 \cdot 160$ & $0.03,0.29$ & 0.057 & -0.29 & 0.003 \\
\hline Very good & 275 & 0.323 & $0.21,0.43$ & Ref. & 0 & Ref. \\
\hline Is your baby easy to feed?† & & & & & Total & 0.001 \\
\hline Average & 146 & $0 \cdot 196$ & $0.04,0.35$ & 0.503 & 0.20 & 0.080 \\
\hline Easy & 237 & 0.262 & $0.14,0.39$ & Ref. & 0 & Ref. \\
\hline Very easy & 177 & $0 \cdot 168$ & $0.03,0.30$ & $0 \cdot 318$ & -0.29 & 0.006 \\
\hline
\end{tabular}

${ }^{*}$ Including all other variables in table. $R^{2}$ for whole multivariable model $=0 \cdot 08$.

tThis variable was significant $P<0.2$ in univariate analysis before recoding from five to three response categories.

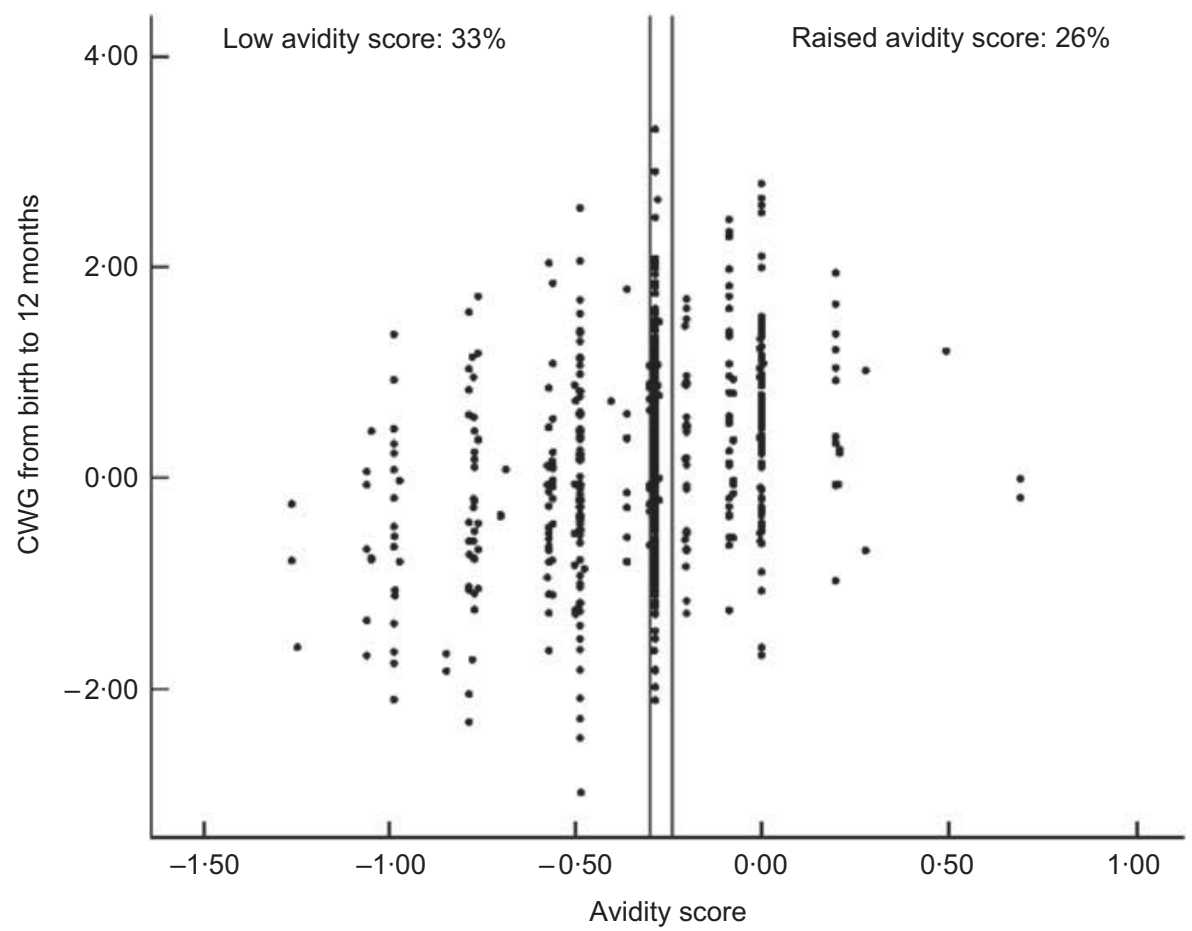

Fig. 1 Relationship between infant avidity score and conditional weight gain (CWG) from birth to 12 months: Gateshead Millennium Study cohort

mislead, particularly if children have unusual body composition $^{(33)}$ or activity levels ${ }^{(34)}$. In the present study the avidity score was associated with BMI at age 7 years, but not with adiposity, probably reflecting the combined association of BMI with height and lean mass, rather than fat mass. One strength of the study is the wide range of body composition measures used. Measures of body composition are all relatively imprecise and prone to a range of biases $^{(35)}$, but using different techniques should allow a 'triangulation' of the estimates. The adiposity index summarises that process, with the aim of arriving at an average value that should be more precise and accurate. A limitation 
Table 5 Association of infant avidity score at 12 months with growth and body composition measures at age 7 years: Gateshead Millennium Study cohort

\begin{tabular}{|c|c|c|c|c|c|c|}
\hline & \multicolumn{3}{|c|}{ Univariable correlation coefficient } & \multicolumn{3}{|c|}{ Partial correlation adjusted for height } \\
\hline & $n$ & $r$ & $P$ & $n$ & $r$ & $P$ \\
\hline \multicolumn{7}{|l|}{ All } \\
\hline Height & 426 & $0 \cdot 11$ & 0.02 & - & - & - \\
\hline BMI & 424 & $0 \cdot 13$ & $0 \cdot 01$ & 421 & $0 \cdot 10$ & 0.04 \\
\hline Lean mass (BIA) & 423 & $0 \cdot 10$ & 0.05 & 420 & 0.08 & 0.09 \\
\hline Adiposity index & 329 & 0.08 & $0 \cdot 17$ & 326 & 0.04 & 0.53 \\
\hline \multicolumn{7}{|l|}{ Boys } \\
\hline Height & 210 & $0 \cdot 14$ & 0.04 & - & - & - \\
\hline BMI & 209 & $0 \cdot 17$ & $0 \cdot 01$ & 206 & $0 \cdot 13$ & 0.07 \\
\hline Lean mass (BIA) & 210 & 0.07 & 0.29 & 207 & 0.05 & 0.45 \\
\hline Adiposity index & 161 & $0 \cdot 12$ & $0 \cdot 11$ & 158 & 0.08 & 0.29 \\
\hline \multicolumn{7}{|l|}{ Girls } \\
\hline Height & 216 & 0.08 & $0 \cdot 22$ & - & - & - \\
\hline BMI & 215 & $0 \cdot 10$ & $0 \cdot 14$ & 212 & 0.07 & 0.28 \\
\hline Lean mass (BIA) & 213 & $0 \cdot 12$ & 0.07 & 210 & $0 \cdot 11$ & $0 \cdot 10$ \\
\hline Adiposity index & 168 & 0.05 & 0.57 & 165 & 0.003 & 0.97 \\
\hline
\end{tabular}

BIA, bioelectrical impedance.

Values are Pearson's correlation coefficients $(r)$ of each measure, expressed as a Z-score, with infant avidity score.

is that the adiposity index requires complete data for six different measurements, which means that it was available for even fewer children than the single measures.

\section{Conclusions}

While rapid weight gain in infancy does predict later adiposity, both infancy weight gain and eating avidity predict subsequent height more strongly than adiposity. Those infants who both gained weight rapidly and had a relatively high BMI at the age of 1 year did have a nearly threefold greater risk of high adiposity at age 7 years; but even among these infants, a majority did not go on to have high adiposity at age 7 years. So what does this imply for directing interventions to 'high-risk' infants? Even parents of older children are often unaware that their children are overweight $^{(36)}$ and unwilling to institute change ${ }^{(37)}$. As infancy is a time when rapid growth and weight gain have great priority for parents, much more specific indicators than weight gain or eating behaviour are going to be needed if targeted interventions are to be either acceptable or effective.

\section{Acknowledgements}

Sources of funding: The Gateshead Millennium Study was supported by a grant from the National Prevention Research Initiative (incorporating funding from the British Heart Foundation; Cancer Research UK; the Department of Health; Diabetes UK; the Economic and Social Research Council; the Food Standards Agency; the Medical Research Council; the Research and Development Office for Northern Ireland Health and Social Services; the Chief Scientist Office, Scottish Government Health Directorates; the Welsh Assembly Government; and the World Cancer Research
Fund) and the present analysis was undertaken with further funding from the Chief Scientist Office, Scottish Government UK. The cohort was first established with funding from the Henry Smith Charity and Sport Aiding Research in Kids (SPARKS) and followed up with grants from Gateshead NHS Trust R\&D, Northern and Yorkshire NHS R\&D, and the Northumberland, Tyne and Wear NHS Trust. Conflict of interest: None of the authors have any conflicts of interest. Author contributions: C.M.W. ran the infancy phase and helped plan the childhood phases of the study, participated in the analysis and drafted the paper. A.J.A. planned and ran the childhood phase of the study. M.S.P. produced the adiposity index. K.M.C. undertook the main analyses, supervised by A.S., and helped draft the paper. All authors have seen and commented on the manuscript. Acknowledgements: Thanks are especially due to the Gateshead Millennium Study families and children for their participation in the study and to the research team for their efforts. The authors appreciate the practical support of the Gateshead Health NHS Foundation Trust, Gateshead Education Authority and local schools, and the support of an External Reference Group.

\section{References}

1. Baird J, Fisher D, Lucas P et al. (2005) Being big or growing fast: systematic review of size and growth in infancy and later obesity. BMJ 331, 929.

2. Paul IM, Bartok CJ, Downs DS et al. (2009) Opportunities for the primary prevention of obesity during infancy. $A d v$ Pediatr 56, 107-133.

3. Daniels LA, Magarey A, Battistutta D et al. (2009) The NOURISH randomised control trial: positive feeding practices and food preferences in early childhood - a primary prevention program for childhood obesity. $B M C$ Public Health 9, 387.

4. Cole TJ (2007) Early causes of child obesity and implications for prevention. Acta Paediatr Suppl 96, 2-4. 
5. Chomtho S, Wells JC, Williams JE et al. (2008) Infant growth and later body composition: evidence from the 4-component model. Am J Clin Nutr 87, 1776-1784.

6. Wells JC, Hallal PC, Wright A et al. (2005) Fetal, infant and childhood growth: relationships with body composition in Brazilian boys aged 9 years. Int J Obes (Lond) 29, 1192-1198.

7. Carnell S \& Wardle J (2009) Appetitive traits in children. New evidence for associations with weight and a common, obesity-associated genetic variant. Appetite 53, 260-263.

8. Taveras EM, Scanlon KS, Birch L et al. (2004) Association of breastfeeding with maternal control of infant feeding at age 1 year. Pediatrics 114, e577-e583.

9. Owen CG, Martin RM, Whincup PH et al. (2005) Effect of infant feeding on the risk of obesity across the life course: a quantitative review of published evidence. Pediatrics 115, 1367-1377.

10. Agras WS, Kraemer HC, Berkowitz RI et al. (1990) Influence of early feeding style on adiposity at 6 years of age. J Pediatrics 116, 805-809.

11. Agras WS, Kraemer HC, Berkowitz RI et al. (1987) Does vigorous feeding style influence early development of adiposity? J Pediatr 110, 799-804.

12. Parkinson KN, Pearce MS, Dale A et al. (2011) Cohort profile: the Gateshead Millennium Study. Int J Epidemiol 40, 308-317.

13. Wright CM, Parkinson KN \& Drewett RF (2004) Why are babies weaned early? Data from a prospective population based cohort study. Arch Dis Child 89, 813-816.

14. Wright CM, Stone D \& Parkinson KN (2010) Undernutrition in British Haredi infants within the Gateshead Millennium Cohort Study. Arch Dis Child 95, 630-633.

15. Freeman JV, Cole TJ, Chinn S et al. (1995) Cross sectional stature and weight reference curves for the UK, 1990. Arch Dis Child 73, 17-24.

16. Wright CM, Parkinson KN \& Drewett RF (2006) The influence of maternal socioeconomic and emotional factors on infant weight gain and weight faltering (failure to thrive): data from a prospective birth cohort. Arch Dis Child 91, 312-317.

17. McCarthy HD, Jarrett KV \& Crawley HF (2001) The development of waist circumference percentiles in British children aged 5.0-16.9 y. Eur J Clin Nutr 55, 902-907.

18. Tanner JM \& Whitehouse RH (1975) Revised standards for triceps and subscapular skinfolds in British children. Arch Dis Child 50, 142-145.

19. Sherriff A, Wright CM, Reilly JJ et al. (2009) Age- and sexstandardised lean and fat indices derived from bioelectrical impedance analysis for ages 7-11 years: functional associations with cardio-respiratory fitness and grip strength. BrJ Nutr 101, 1753-1760.

20. Wright CM, Parkinson KN, Shipton D et al. (2007) How do toddler eating problems relate to their eating behavior, food preferences, and growth? Pediatrics 120 e1069-e1075.

21. Wright CM, Cox KM \& Le Couteur A (2011) How does infant behaviour relate to weight gain and adiposity? Proc Nutr Soc (In the Press).

22. Demerath EW, Reed D, Choh AC et al. (2009) Rapid postnatal weight gain and visceral adiposity in adulthood: the Fels Longitudinal Study. Obesity (Silver Spring) 17, 2060-2066.

23. Cameron N, Pettifor J, De Wet $\mathrm{T}$ et al. (2003) The relationship of rapid weight gain in infancy to obesity and skeletal maturity in childhood. Obes Res 11, 457-460.

24. Blair NJ, Thompson JM, Black PN et al. (2007) Risk factors for obesity in 7-year-old European children: the Auckland Birthweight Collaborative Study. Arch Dis Child 92 866-871.

25. Ong KK, Emmett P, Northstone K et al. (2009) Infancy weight gain predicts childhood body fat and age at menarche in girls. J Clin Endocrinol Metab 94, 1527-1532.

26. Carnell S \& Wardle J (2008) Appetite and adiposity in children: evidence for a behavioral susceptibility theory of obesity. Am J Clin Nutr 88, 22-29.

27. Webber L, Hill C, Saxton J et al. (2009) Eating behaviour and weight in children. Int J Obes (Lond) 33, 21-28.

28. Spruijt-Metz D, Lindquist CH, Birch LL et al. (2002) Relation between mothers' child-feeding practices and children's adiposity. Am J Clin Nutr 75, 581-586.

29. Johnson SL \& Birch LL (1994) Parents' and children's adiposity and eating style. Pediatrics 94, 653-661.

30. Ashcroft J, Semmler C, Carnell S et al. (2008) Continuity and stability of eating behaviour traits in children. Eur $J$ Clin Nutr 62, 985-990.

31. Wardle J \& Carnell S (2009) Appetite is a heritable phenotype associated with adiposity. Ann Behav Med 38, $25-30$.

32. Haworth CM, Carnell S, Meaburn EL et al. (2008) Increasing heritability of BMI and stronger associations with the FTO gene over childhood. Obesity (Silver Spring) 16, 2663-2668.

33. Wright CM, Sherriff A, Ward SC et al. (2008) Development of bioelectrical impedance-derived indices of fat and fatfree mass for assessment of nutritional status in childhood. Eur J Clin Nutr 62, 210-217.

34. Wells JC (2003) Body composition in childhood: effects of normal growth and disease. Proc Nutr Soc 62, 521-528.

35. Parker L, Reilly JJ, Slater C et al. (2003) Validity of six field and laboratory methods for measurement of body composition in boys. Obes Res 11, 852-858.

36. Parkinson KN, Drewett RF, Jones AR et al. (2011) When do mothers think their child is overweight? Int J Obes (Lond) 35, 510-516.

37. Towns N \& D'Auria J (2009) Parental perceptions of their child's overweight: an integrative review of the literature. J Pediatr Nurs 24, 115-130. 